\title{
EL SEPULCRE D'ALFONS EL CAST A POBLET
}

\author{
GENER GONZALVO I BOU \\ Arxiu Històric Comarcal \\ (Tàrrega, Lleida)
}

Ja durant l'Alta Edat Mitjana, els grans llinatges reials i nobiliaris escollien esglésies i monestirs per a sebollir els cossos de les seus familiars. Era una qüestió de prestigi del llinatge, i també perquè poguessin gaudir de les oracions, pregàries $\mathrm{i}$ aniversaris de preveres $\mathrm{o}$ religiosos del centre monàstic escollit, a més de tenir properes les relíquies dels sants.

Això que comentem és el cas del casal reial d'Aragó, que escollí principalment el monestir de Sant Joan de la Penya com a lloc o santuari de la família reial. Pel que fa al casal de Barcelona, des de Guifre el Pelós fou escollit el monestir benedictí de Ripoll. Els darrers comtes a enterrar-se a Ripoll foren els grans comtes Ramon Berenguer III i Ramon Berenguer IV.

Com sabem avui, pel 1151 fou fundat el monestir de Santa Maria de Poblet pel comte de Barcelona Ramon Berenguer IV, encomanant-lo als cistercencs del llanguedocià cenobi de Fontfreda. De fet, aquest gran comte, que aconseguiria la conquesta de la Catalunya Nova amb la caiguda de Lleida i Tortosa, encarregaria als cistercencs la repoblació de noves terres conquerides als musulmans. El mateix paper jugaria el monestir germà de Santes Creus, a la conca del Gaià. El segle XII és, doncs, el moment del gir de la política catalana, amb l'impuls de la Catalunya Nova, amb detriment dels comtats de l'antiga Catalunya Vella. Cistercencs, templers, hospitalers i cartoixans (Escaladei) serien els encarregats d'impulsar aquesta nova Catalunya, amb el ressorgiment de les ciutats i de la vida urbana, i amb les cartes de franquícies atorgades pels comtes i comtes-reis als nous pobladors.

"Anuario de Estudios Medievales", 30/2 (2000) 
El monestir de Poblet va nèixer, doncs, sota la protecció del casal de Barcelona, empara que imitarien altres alts llinatges nobiliaris catalans, com els Cardona o els Cervera. Totes aquestes famílies volgueren també escollir Poblet com a lloc de sepultura, fet que convertiria el cenobi de la Conca de Barberà, amb el pas del temps, amb un gran mausoleu nobiliari.

Com hem dit, el fundador de Poblet encara seria enterrat al monestir de Ripoll (avui dia, la seva tomba és malauradament desapareguda, pels avalots del 1835). El seu fill, Alfons, seria una figura que dotaria d'un gran canvi al casal de Barcelona: seria investit amb la dignitat reial d'Aragó. Alfons I i el seu reialme s'insereix dins el context europeu d'assentament de les grans monarquies per sobre dels llinatges feudals. Alfons hagué de suportar moltes revoltes al país, però com molt bé ha estudiat Thomas Bisson, aconseguiria assentar la monarquia catalanoaragonesa.

Alfons I el Cast continuà la protecció del monestir de Poblet iniciada pel seu pare, amb nombrosos privilegis. Confirmà les propietats del monestir, tot facilitant les pastures, ramats i del gran bosc pobletà. Féu també diverses donacions al monestir, i per exemple, el dret de pesca a l'estany de Pineda, prop de Salou, l'any $1195^{1}$. També és ben conegut que amb gran interès imulsà les obres de construcció monàstiques pobletanes, en especial de la gran església major, començada i acabada al segle XII en el més pur estil cistercenc.

El 1176, des d'Anglesola, a l'Urgell, el rei Alfons, que professava una gran devoció pels cistercencs i per Poblet, escollí el monestir pobletà com a lloc de la seva sepultura. Hi posà, però, una condició: en cas de poder conquerir València - una obsessió que el perseguí al llarg de tot el seu regnat-, volia ser sepultat al monestir que Poblet havia de fundar a Cepolla, nom antic de Puig de Santa Maria, indret del qual havia fet donació a Poblet per a fer-hi una fundació monàstica².

Com que les terres valencianes no foren conquerides fins al segle XIII, per Jaume I, Alfons I el Cast -mort a Perpinyà el 1196- fou sebollit al monestir de Poblet, convertint el monestir de la Conca de Barberà en panteó reial dels Casals d'Aragó i de Barcelona, trencant així amb les

'Joan PONS I MARQuÈs, Cartulari de Poblet. Edició del manuscrit de Tarragona, Barcelona, 1938, doc. 261, pp. 157-158.

${ }^{2}$ Joan PONS I MARQUÈs, Cartulari de Poblet. Edició del manuscrit de Tarragona, citat, doc. 29, pp. 11-12. 
tradicions de Sant Joan de la Penya i Ripoll. El seu desig d'enterrar-se a Poblet el ratificà en el seu testament de 31 de juliol de 1194 atorgat a Perpinyà, i en el codicil d'abril del 1996, davant Joan Bau, va ordenar el mateix $^{3}$. En aquests documents el rei donava també a Poblet la seva corona reial, com a símbol de poder i sobirania d'aquest nou estat que Alfons ha construït ${ }^{4}$, el seu domini de Vinaròs i al vinya de la Palomera, prop de Lleida. Encara més, disposà que el seu tercer fill, Ferran, es consagrés com a monjo cistercenc de Poblet ${ }^{5}$.

El cadàver d'Alfons I el Cast, un cop mort a Perpinyà, fou traslladat al monestir de Poblet a finals del segle XII. La seva sepultura primitiva sembla que fou una simple caixa de fusta folrada de tela ricament decorada, i col·locada al presbiteri de l'església monàstica. Al segle XIII, en front hi seria col-locada la tomba de Jaume I, al mateix presbiteri de l'església monàstica pobletana. Els cronistes del monestir de Poblet situen la primitiva tomba d'Alfons I al costat de l'epístola del presbiteri, però això darrer és difícil de provar, ateses les grans reformes del panteó reial portades a terme per Pere III, al segle XIV.

Com dèiem, fou Pere III el qui ideà el panteó reial de Poblet dels comtes-reis del casal de Barcelona. Fou un llarg procés iniciat amb l'abat Ponç de Copons, i acabat sobretot amb l'abadiat de Guillem d'Agulló. En un principi, Pere III només volia uns sarcòfags per a la seva sepultura i les seves mullers. El procés, llarg d'explicar, i que comença el 1340, no s'escau d'explicar-lo ací, car no és el lloc indicat. El que sí podem dir és que, primerament, el rei Pere pensà fer esculpir un sarcòfag per a Jaume I, i posteriorment un de nou per al rei Alfons el Cast. Cap al 1364, el rei Pere tingué la idea de construir dos arcs rebaixats al creuer de l'església de Poblet, en lloc de posar el sepulcres al terra, i col-locar-hi les sepultures esculpides per Jaume Cascalls, d'Alfons I, Jaume I, i la seva pròpìa i la de les seves mullers. El rei Pere, pel que fa al rei Alfons, manà que es fes una nova

${ }^{3}$ Pròsper de Bofarull, Colección de Documentos Inéditos del Archivo General de la Corona de Aragon, IV, Barcelona, 1849, p. 395.

${ }^{4}$ José Enrique RuIz DOMÈNEC, A propósito de Alfonso, rey de Aragón, conde de Barcelona y marqués de Provenza, Barcelona, Real Academia de Buenas Letras de Barcelona, 1996, pp. 143-144.

${ }^{5}$ Jerónimo ZURITA, Anales de la Corona de Aragón, I, Saragossa, 1562, llib. II, cap. 47. Per als panteons reials de Poblet, podeu consultar Ricardo DEL ARCO, Sepulcros de la casa real de Aragón, Madrid, 1945. 
estàtua jacent, i amb escenes de processó fúnebre i de cavallers. Més endavant, el rei canvià d'opinió, i la sepultura del rei Alfons havia de tenir doble representació escultòrica: una vestit de monjo, i una altra de rei. L'encàrrec reial fou finalment portat a terme, i sabem que el cos del rei Alfons el Cast fou portat sobre l'arc, pels volts del 1390. Abans, el rei Pere ja havia disposat (1377) que els seus successors fossin enterrats al monestir pobletà, convertint així Poblet en panteó central de la corona catalanoaragonesa ${ }^{6}$.

Abans de la destrucció del cenobi, al segle XIX, diversos cronistes i historiadors ens descriuen el panteó reial de Poblet, al qual hi fou incorporat, al segle XVII, el panteó ducal de la casa de Cardona.

El famós historiador de la casa, el P. Jaume Finestres, deixà una obra, fins ara inèdita, en què ens descriu amb detall tot el cenobi pobletà. Sobre el sepulcre d'Alfons I, diu el Pare Finestres: «En los referidos seis reales sepulcros estan enterrados los sereníssimos Señores Reyes de Aragón por el orden siguiente. En el primero y mas immediato al Presbiterio por la parte de la Epístola yace el Rey D. Alfonso II, que murió a 24 de abril del año 1196. Tiene sobre la tapadera del sepulcro dos estatuas, o imagenes suyas de alabastro tendidas, una a la parte de la Capilla Real [l'espai que quedava entre els dos arcs del panteó reial] vestido con habito de Diacono, y Corona de laurel en la cabeza ${ }^{7}$ y a la parte que mira al cementerio con cogulla cisterciense, Habito con que quiso ser sepultado por la mucha devocion que tuvo a la Orden y a este Monasterio»"

La mateixa descripció fa de la tomba del rei Alfons I l'il·lustre viatger Antonio Ponz, que visità Poblet i les seves riqueses a finals del segle XVIII, i que publicà en el seu famós "Viage de España"9. Un dels últims noms il-lustres que pogueren veure l'esplendor de les tombes de Poblet, a principis del segle XIX fou el P. Jaume Villanueva, a més dels gravats deixats per

${ }^{6}$ Sobre el procés de construcció dels panteons reials en temps de Pere el Cerimoniós, vegeu Agustí AltisEnT, Història de Poblet, Poblet, 1974, pp. 262-296.

${ }^{7}$ És ben sabut que a Alfons el Cast se li atribueixen diverses composicions poètiques, i d'aquí aquesta representació. Ja sabem també que Alfons també era anomenat "El Trovador".

${ }^{8}$ Jaume FINESTRES, Epitome Historico de el Real Monasterio de Santa Maria de Poblet, AHN, Còdex $777 \mathrm{~B}$, fol. $17 \mathrm{v}$.

${ }^{9}$ Antonio PonZ, Viage de España, XIV, Madrid, 1788, p. 221. 
Alexandre de Laborde i de Francesc Xavier Parcerisa, que ens donen una idea de la gran bellesa, única a Europa, dels panteons pobletans.

Amb la desamortització del 1835, vingué l'abandó de Poblet. Els sepulcres reials fores violats i destruïts el 1839 , i els cossos reials llençats pel paviment de l'església. El rector de l'Espluga de Francolí els recollí, i els guardà a la parroquial espluguina. A mitjan segle XIX, es realitzà un projecte per guardar i construir dos panteons reials a la catedral de Tarragona. Els migrats pressupostos feren que només se'n construís un per a Jaume I, mentre que les restes d'Alfons el Cast i la resta de reis i reines restessin abandonades a les dependències catedralícies tarragonines, per a vergonya del país, tal com denuncià l'august patrici Eduard Toda i Güell ${ }^{10}$.

No és fins al 1940, amb el retorn de la comunitat cistercenca a Poblet, que es comença a parlar de la restauració de les tombes reials. Finalment, foren refetes en un estil neogòtic i historicista per l'escultor Frederic Marès. La nova tomba d'Alfons el Cast fou col·locada segons les antigues descripcions de les sepultures reials, i aprofitant alguns fragments de la seva antiga sepultura. El nou i definitiu sepulcre fou inaugurat el $1952^{11}$.

\section{RÉSUMÉ}

Le roi Alfons I a continué avec la protection que son père, le comte Ramon Berenguer IV avait déjà professée par Poblet. Comme toutes les grandes monarchies, il a élu comme panthéon un remarquable monastère, comme il l'était déjà Poblet au XIF̈me siècle, par testament de 1176. Il a été enterré vers la fin du Xİ̀me siècle au panthéon royal conçu par le roi Pere III. Il est resté là jusqu'à la destruction de 1835, jusqu'au moment où le sculpteur Frederic Marès a restauré son tombeau, inauguré l'an 1952.

\section{SUMMARY}

King Alfons I continued the protection that his father, Count Ramon Berenguer IV, had professed for Poblet. Like all the great monarchs, he chose a great monastery, as Poblet was in the 12th century, in his 1176 will. He was buried at the end of the 12th century and

\footnotetext{
${ }^{10}$ Eduard TodA, Panteones reales de Poblet, Tarragona, 1935. Vegeu també, del mateix autor, La destrucció de Poblet, Poblet, 1935.

${ }^{1 " F e d e r i c o ~ M A R E ̀ S ~ D E ́ U L O V o l, ~ L a s ~ T u m b a s ~ R e a l e s ~ d e ~ l o s ~ M o n a r c a s ~ d e ~ C a t a l u n ̃ a ~ y ~ A r a g o ́ n ~}$ del Monasterio de Santa María de Poblet, 2a. edició, Poblet, 1998.
} 
incorporated into the royal pantheon designed by Peter III in the 14th century. He remained there until the destruction of 1835 , until the sculptor Frederic Marès restored his tomb, which was inaugurated in 1952. 